\title{
Article \\ Silicon Enhances Resistance to Red Crown Rot Caused by Calonectria ilicicola in Soybean
}

\author{
Khin Thuzar Win, Satoru Maeda, Michie Kobayashi and Chang-Jie Jiang * (D) \\ Institute of Agrobiological Sciences, National Agriculture and Food Research Organization (NARO), \\ Tsukuba 305-8602, Japan; kint688@affrc.go.jp (K.T.W.); satorum@affrc.go.jp (S.M.); \\ kobayashim856@affrc.go.jp (M.K.) \\ * Correspondence: cjjiang@affrc.go.jp; Tel.: +81-2988388385
}

Citation: Win, K.T.; Maeda, S.;

Kobayashi, M.; Jiang, C.-J. Silicon

Enhances Resistance to Red Crown Rot Caused by Calonectria ilicicola in Soybean. Agronomy 2021, 11, 899. https://doi.org/10.3390/ agronomy11050899

Academic Editor: Yuba Kandel

Received: 20 April 2021

Accepted: 1 May 2021

Published: 3 May 2021

Publisher's Note: MDPI stays neutral with regard to jurisdictional claims in published maps and institutional affiliations.

Copyright: (c) 2021 by the authors. Licensee MDPI, Basel, Switzerland. This article is an open access article distributed under the terms and conditions of the Creative Commons Attribution (CC BY) license (https:// creativecommons.org/licenses/by/ $4.0 /)$.
Abstract: Silicon (Si) application is known to enhance plant resistance to diverse pathogens. Therefore, a greenhouse study was conducted to determine whether Si reduces red crown rot (RCR) of soybean caused by the soil-borne fungal pathogen Calonectria ilicicola. The soybean cultivar Enrei was grown in soil mixed with different concentrations of sodium silicate $\left(\mathrm{Na}_{2} \mathrm{SiO}_{3}\right)$ and inoculated with $C$. ilicicola $(1 \% w / v)$. Si application significantly reduced RCR severity and relative fungal growth in the roots, as per qPCR, at both sampling time points. Notably, the shoot Si content correlated significantly with RCR severity in the roots. In addition, $\mathrm{Si}$ application reduced the accumulation of malondialdehyde, indicating that the maintenance of cellular membrane integrity is an important mechanism underlying Si-mediated protection of soybean plants from RCR. Furthermore, Si-treated plants exhibited improved water and nitrogen uptake and root and shoot growth. Aboveground biomass and seed yield at harvest increased with increasing $\mathrm{Si}$ concentration $\left(0.0-3.0 \mathrm{~g} \mathrm{Na}_{2} \mathrm{SiO}_{3} \mathrm{~kg}^{-1}\right.$ soil). However, further increase in $\mathrm{Si}$ concentration $\left(6.0 \mathrm{~g} \mathrm{Na}_{2} \mathrm{SiO}_{3} \mathrm{~kg}^{-1}\right.$ soil) reduced seed yield. Therefore, Si treatment can be used as an effective strategy to control RCR in soybean.

Keywords: soybean; red crown rot; Calonectria ilicicola; silicon; disease resistance

\section{Introduction}

Soybean (Glycine max (L.) Merr.) is one of the most economically important agricultural crops in the world, providing abundant vegetable protein and edible oil for human consumption and animal feed. However, it has recently been estimated that as much as $11-32 \%$ of the global soybean yield is lost annually owing to diseases caused by diverse pathogens and pests. Among these, the soil-borne fungal pathogen Calonectria ilicicola Boedijin and Reitsma (anamorph Cylindrocladium parasiticum Crous, Wingfield, and Alfennas) causes red crown rot (RCR) [1-3]. The disease is characterized by root rot, damping-off of young seedlings, and early defoliation [4-7], and it is mostly encountered by seedlings growing in poorly drained soils, with high clay content, and subjected to temporary flooding and ponding.

RCR is one of the most severe diseases affecting soybean in Japan, because more than $80 \%$ of the soybean crops are cultivated in paddy-converted fields [8]. The clayey nature of these soybean fields is favorable for paddy cultivation, making them prone to short-term water logging because of poor drainage [9]. It has been estimated that soybean yield losses from C. ilicicola range from 25 to $30 \%[10,11]$ to as high as $50 \%$, especially in a susceptible cultivar, depending on the occurrence of the environmental conditions that favor fungal colonization [3].

Thus, it is very important to develop effective methods and new disease management strategies that guarantee sustainable long-term soybean production to combat this pathogen, as neither C. ilicicola-resistant commercial cultivars nor effective fungicides are currently available in the market [12]. One alternative to chemical control of RCR relies 
on silicon ( $\mathrm{Si})$, whose application reportedly decreases the severity of several fungal diseases in economically important crops [13-16]. Although seemingly not essential for plant growth, Si has been recognized to play a vital role in effectively mitigating various environmental stress factors and enhancing plant resistance against both fungal and bacterial pathogens [16-18].

It has been reported that in soybean, Si may accumulate on the tissue surface or root cell walls, acting as a physical barrier to prevent pathogen penetration and to render plant cells less susceptible to enzymatic degradation by fungal pathogens [16,19-21]. Furthermore, Si functions as a signal that induces the production of various chemical defense agents against pathogens $[14,15]$. In soybean, $\mathrm{Si}$ has been reported to reduce disease severity caused by Phytophthora sojae (root and stem rot) [22,23], Cercospora sojina (frogeye leaf spot) [21,24,25], Phakopsora pachyrhizi (Asian soybean rust) [21,26,27], and Peronospora manshurica (downy mildew) [21] However, little is known about the underlying molecular mechanisms whereby Si alleviates stress in legumes [20]. Moreover, the possible effects of Si on RCR in soybean has not been investigated.

The objective of this study was to investigate the effects of Si application on RCR development in young soybean seedlings. We observed that $\mathrm{Si}$ application significantly reduced RCR incidence and partially rescued plant growth and seed yield in soybean.

\section{Materials and Methods}

\subsection{Plant Growth Conditions and Si Application}

The soybean cultivar Enrei was used in the present study. The seeds were preconditioned in a moisture-saturated plastic box for $24-48 \mathrm{~h}$ at $25^{\circ} \mathrm{C}$ before sowing. Four seeds of uniform shape and size were planted in 1.5 L plastic pots $(12 \mathrm{~cm} \times 12 \mathrm{~cm} \times 20 \mathrm{~cm})$ filled with $1200 \mathrm{~g}$ of commercial pre-fertilized, granulated soil (Nippi No. 1, Nippon Hiryo, Tokyo, Japan). The chemical composition of the soil was as follows: pH: 5.86.5 and EC: $1.2 \mathrm{mS} / \mathrm{cm}, \mathrm{N}: 220 \mathrm{mg} \mathrm{kg}{ }^{-1}, \mathrm{NH} \_4+: 177 \mathrm{mg} \mathrm{kg}^{-1}, \mathrm{P}: 2775 \mathrm{mg} \mathrm{kg}^{-1}, \mathrm{~K}:$ $220 \mathrm{mg} \mathrm{kg}^{-1}$, and $\mathrm{mg}: 220 \mathrm{mg} \mathrm{kg}^{-1}$. The top of each pot was covered with a $2-\mathrm{mm}$ layer of pre-fertilized peaty soil Supermix-A (Sakata Seed Co. Ltd., Yokohama, Japan). One day before sowing, both the soils used in this study were autoclaved at $120^{\circ} \mathrm{C}$ for $1 \mathrm{~h}$ to eliminate soil pathogens. Plants were grown in May 2020, in a temperature-adjustable greenhouse at $25 / 20^{\circ} \mathrm{C}$ (day /night), at $50 \% \mathrm{RH}$, under natural light conditions. Water was supplied ad libitum to the container to maintain high soil moisture content until the assay was completed.

The seeded pots were arranged in a completely randomized design in the greenhouse to minimize any positional effects, and all experiments were conducted using three replicates, each consisting of four plants per pot. Sodium silicate $\left(\mathrm{Na}_{2} \mathrm{SiO}_{3}\right)$ was used as the Si source and mixed at concentrations of 0 (control), $0.5,1.0,3.0$, and $6.0 \mathrm{~g} \mathrm{~kg}^{-1}$ of soil in the pots, corresponding to $0,0.05,0.1,0.30$, and $0.59 \mathrm{~g}$ of elemental Si kg ${ }^{-1}$ of soil. Plants grown in control pots were not infected with $C$. ilicicola and were used as the un-inoculated control (mock).

\subsection{Pathogen Culture and Inoculation}

In this study, C. ilicicola isolate UH2-1 was used owing to its high and stable virulence [12]. UH2-1, which was isolated from RCR-diseased soybean roots from Sasayama, Hyogo, was kindly provided by Dr. Sunao Ochi (Research Center for Agricultural Information Technology, NARO, Japan) [12]. Fungal mycelia were grown on potato dextrose agar (PDA) plates at $25^{\circ} \mathrm{C}$ for 1-2 weeks or until mycelial growth reached the edges of the petri plates.

Pathogen inoculation was performed as described previously [12]. Briefly, $5-8$ pieces $(\approx 5$-mm cubes) of PDA with vigorous $C$. ilicicola mycelial growth were placed in a $500 \mathrm{~mL}$ flask containing $200 \mathrm{~g}$ of wheat bran-vermiculite medium (wheat bran/vermiculite/water 1:1:3, $w / w / v$, autoclaved at $120{ }^{\circ} \mathrm{C}$ for $20 \mathrm{~min}$ ) and incubated at $26^{\circ} \mathrm{C}$ for $10-14 \mathrm{~d}$ until fungal mycelia completely covered the medium. This culture was used as the inoculum, 
and an inoculum-soil mixture was prepared using the inoculum with Nippi No. 1 soil at a concentration of $1 \%(w / v)$. The mixture was placed into the previously described plastic pots $(1.5 \mathrm{~L})$, in which four seeds were sown per pot.

\subsection{Measurement of Disease Severity and Relative Fungal Growth}

Three and six weeks post sowing and inoculation (WPI), the aboveground plant parts were harvested from the pots. The roots were washed gently under running tap water to remove the adhering soil, excised at the hypocotyl, blot-dried on a paper towel to remove excess water, and their fresh weights were measured.

The disease severity on the roots was visually scored based on a six-point scale (0-5) as described previously [12,28]: $0=$ no visible symptom, $1=$ small brown necrotic lesions on the primary root, $2=$ brown necrotic lesions extending all over the primary root and some lateral roots, $3=\geq 50 \%$ root-loss owing to rot and severe brown necrosis on the subterranean stem, $4=$ approximately $100 \%$ roots lost to rot, and $5=$ seedling death. Individual seedlings were considered dead if they had withered and fallen.

Relative fungal growth was estimated using real-time qPCR. Genomic DNA was extracted from the roots using MagExtractor (Toyobo, Osaka, Japan) following the manufacturer's instructions. Each replicate was represented by three roots, and there were three technical replicates for each treatment, along with three biological replicates $(n=27)$. qPCR was performed on a Thermal Cycler Dice Real Time System TP800 (Takara, Tokyo, Japan) using SYBR premix Ex Taq II (Takara, Tokyo, Japan) with cycles at $95{ }^{\circ} \mathrm{C}$ for $5 \mathrm{~s}$ (denaturation), $55{ }^{\circ} \mathrm{C}$ for $20 \mathrm{~s}$ (annealing), and $72{ }^{\circ} \mathrm{C}$ for $20 \mathrm{~s}$ (extension). The PCR primers used are as follows: (1) primers targeting the intergenic spacer region of the C. ilicicola rDNA: CiIGSF (forward) $=5^{\prime}$-TCCATTGCCTCTATTTATCCTGC $-3^{\prime}$ and CiIGSR (reverse) $=5^{\prime}$-GCGTAAAGATTTTCCAACCCG-3' [29]; (2) primers for soybean actin gene 11 (Glyma.15G050200): GmActinF (forward) $=5^{\prime}$-GAGCTATGAATTGCCTGATGG-3') and GmActinR (reverse) $=5^{\prime}$-CGTTTCATGAATTCCAGTAGC-3' [30]. Relative fungal growth was expressed as a C. ilicicola rDNA amplification fold relative to the host actin gene amplification [12].

\subsection{Measurement of Plant Growth Parameters}

At harvest, $120 \mathrm{~d}$ after planting, leaves, shoots, and roots were separated, and the total leaf area (TLA), seed yield, and dry weights (DWs) of the aboveground plant parts were recorded. TLA was measured using the software ImageJ, and seed yield was adjusted to $14 \%$ moisture content. Additionally, the fresh weight (FW) of each part was recorded, which was followed by oven-drying at $70{ }^{\circ} \mathrm{C}$ for $7 \mathrm{~d}$ to determine the dry weight (DW).

After estimating the disease symptoms at 3 WPI, whole roots were gently washed with deionized water and stored in $70 \%$ ethanol until measurements of root growth parameters. The root surface area, total root length, and total root tips were measured using an image analyzer Win-RHIZO REG V 2004 b (Regent Inc., Quebec, QC, Canada).

\subsection{Measurement of Leaf Relative Water Content (RWC)}

Leaf RWC was determined between 8:30 and 10:00 a.m. at 3 and 6 WPI. Fully expanded second trifoliate leaves from the top were used to determine the RWC by sampling 12 leaf discs (diameter: $7 \mathrm{~mm}$ ). These leaf discs were excised using a loose leaf punch, placed immediately into a sample bag in an ice box, and their FWs were immediately recorded. Subsequently, they were placed in distilled water in a closed container and incubated for $12 \mathrm{~h}$ at $4{ }^{\circ} \mathrm{C}$ in the dark. Then, they were removed from the water, pat-dried using Kimwipes, and immediately weighed to obtain the turgid weight (TW). The DWs of the discs were obtained after oven-drying for $7 \mathrm{~d}$ at $70{ }^{\circ} \mathrm{C}$, and the RWC was determined using the following equation [31]:

$$
\text { RWC }=\frac{\text { Fresh weight }(\mathrm{FW})-\text { Dry weight }(\mathrm{DW})}{\text { Fully turgid weight }(\mathrm{TW})-\text { Dry weight }(\mathrm{DW})} \times 100 .
$$




\subsection{Determination of Si and N Content}

Shoots were analyzed for Si accumulation and N content at 3 WPI and 6 WPI. After harvesting, dried shoots were ground to a powder using a high-speed vibrating sample mill TI-500ET (CMT Col Ltd., Tochigi, Japan) and then dried at $60^{\circ} \mathrm{C}$ for $24 \mathrm{~h}$. Si content was determined using a slightly modified procedure of autoclave-induced digestion [32], whereby $100 \mathrm{mg}$ of leaf powder was mixed with $3 \mathrm{~mL}$ of $50 \% \mathrm{NaOH}$ placed in polypropylene tubes and covered with a loose-fitting plastic cap. The mixture was gently vortexed and then autoclaved at $121{ }^{\circ} \mathrm{C}$ for $20 \mathrm{~min}$. The tubes were removed, and the volume was increased to $50 \mathrm{~mL}$ with distilled water. Leaf Si content was determined colorimetrically as follows: $1 \mathrm{~mL}$ aliquot of the mixture was mixed with $30 \mathrm{~mL} 20 \%$ acetic acid, $10 \mathrm{~mL}$ ammonium molybdate solution ( $\left.54 \mathrm{~g} \mathrm{~L}^{-1}, \mathrm{pH} 7.0\right), 5 \mathrm{~mL} 20 \%$ tartaric acid $\left(20 \mathrm{~g} \mathrm{~L}^{-1}\right)$, and $1 \mathrm{~mL}$ reducing solution. The reducing solution was prepared using $4 \mathrm{~g}$ sodium sulfite, $0.8 \mathrm{~g}$ 1-amino-2-naphthol-4-sulfonic acid, and $50 \mathrm{~g}$ sodium bisulfite in $500 \mathrm{~mL}$ distilled water. The absorbance was measured after $5 \mathrm{~min}$ at $650 \mathrm{~nm}$ using a UV-Vis spectrophotometer (Genesys 10S UV-Vis, Thermo Scientific, Waltham, MA, USA). A series of Si standards $(0-5 \mathrm{ppm})$ prepared from a Si standard solution $(1000 \mathrm{mg} / \mathrm{L}$, Fluka, Sigma-Aldrich, St. Louis, MO, USA) were used to generate a regression equation to determine the final leaf $\mathrm{Si}$ content (mg/kg DW).

Total nitrogen $(\mathrm{N})$ content in the shoots was determined using an NC analyzer (SUMIGRAPH NCH-22F, Sumika Chemical Analysis Service, Osaka, Japan).

\subsection{Assessment of the Effects of Si on Fungal Growth}

To assess the possible direct effects of $\mathrm{Si}$ on the growth of $C$. ilicicola, five concentrations of $\mathrm{Na}_{2} \mathrm{SiO}_{3}$ (i.e., $0.5,1,3,6$, and $10 \mathrm{~g} \mathrm{~L}^{-1}$ ), along with the control (only water), were tested in the laboratory. These solutions were passed through a $0.25 \mu \mathrm{m}$ Millipore filter, added individually to sterilized PDA before solidification (at $60^{\circ} \mathrm{C}$ ), which was stirred continuously with magnetic stirrers to ensure even distribution of $\mathrm{Na}_{2} \mathrm{SiO}_{3}$ and then decanted into sterile 9-cm-diameter petri plates. After solidification, the centers of the plates were inoculated with 7-mm fungal discs and incubated at $25 \pm 1{ }^{\circ} \mathrm{C}$. Five plates per concentration were used for each replicate, and five plates without $\mathrm{Si}$ served as the control. The experiments were conducted using three replicates. Linear growth was recorded at 4 , 10 , and $14 \mathrm{~d}$ after inoculation, and the reduction in linear growth was estimated as follows:

$$
\text { Percentage inhibition }=\frac{(\mathrm{C}-\mathrm{T})}{\mathrm{C}} \times 100
$$

where $\mathrm{C}$ and $\mathrm{T}$ are the colony diameters $(\mathrm{mm})$ in the control and test plates, respectively.

\subsection{Measurement of Malondialdehyde (MDA) Concentration}

Five-day-old soybean seedlings grown on autoclaved soil supplemented with $\left(3 \mathrm{~g} \mathrm{~kg}^{-1}\right.$ of soil) or without Si were inoculated with $5-10 \mathrm{mg}$ of PDA slurry with C. ilicicola mycelia onto the tap roots $(\mathrm{ca} .1 \mathrm{~cm})$. The inoculated seedlings were placed in a moist plastic box and incubated in a growth cabinet at $25^{\circ} \mathrm{C}$. The PDA slurry was prepared by passing it through a syringe, and PDA slurry without $C$. ilicicola mycelia was used as the inoculation control. The inoculated tap roots were sampled at $0,1,2$, and 3 days post-inoculation (DPI) using a clean razor blade, and frozen immediately in liquid nitrogen and stored at $-80{ }^{\circ} \mathrm{C}$ until used for MDA measurement. MDA content was determined using the thiobarbituric acid method and a commercial plant MDA detection kit MAK085-1KT (Sigma-Aldrich, Saint-Quentin Fallavier Cedex, Isère, France). Three biological replicates were used for each seedling.

\subsection{Statistical Analyses}

The raw data were used without mathematical transformation in all the statistical analyses. ANOVA was performed for all measurements using the software STAR 2.0.1 (International Rice Research Institute, Manila, Philippines). The effects of different $\mathrm{Si}$ 
concentrations on fungal growth and sampling times were subjected to two-way ANOVA, and the mean values were compared using Tukey's honest significant difference (HSD) test $(p<0.05)$ in XLSTAT software ver. 2014 (Addinsoft, New York, NY USA). The association between the visual disease score and plant Si uptake was determined using a simple linear regression and Pearson correlation analyses (SigmaPlot version 11.0, Systat Software, Inc., San Jose, CA, USA).

\section{Results}

\subsection{Effect of Si Application on RCR Development in the Roots}

Compared to the un-inoculated control (mock), a remarkable reduction in plant growth was observed upon infection in the inoculated control plants (0 Si). In contrast, Si application alleviated the negative effects of $C$. ilicicola infection on the growth of soybean plants at both sampling time points (Figure 1A,B). Compared to the inoculated control, Si application decreased RCR severity in the roots by $17 \%, 38 \%, 36 \%$, and $36 \%$ at $3 \mathrm{WPI}$ and by $37 \%, 29 \%, 33 \%$, and $34 \%$ at $6 \mathrm{WPI}$, for $0.5,1.0,3.0$, and $6.0 \mathrm{~g} \mathrm{Na}_{2} \mathrm{SiO}_{3} \mathrm{~kg}^{-1}$ of soil, respectively (Figure 1C). The rates of decrease of RCR severity were similar for all Si treatments, and no significant difference was observed at either sampling time point.

(A)

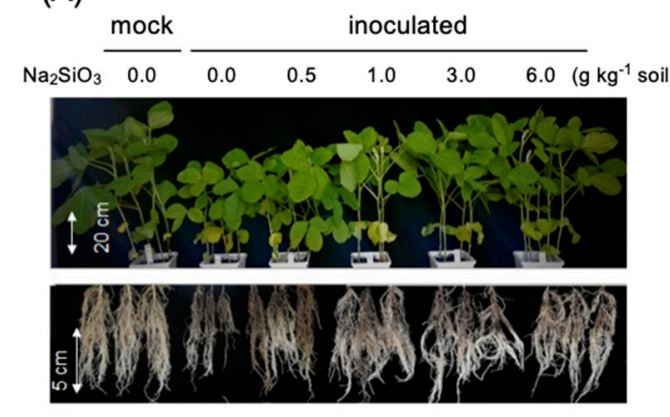

(B)

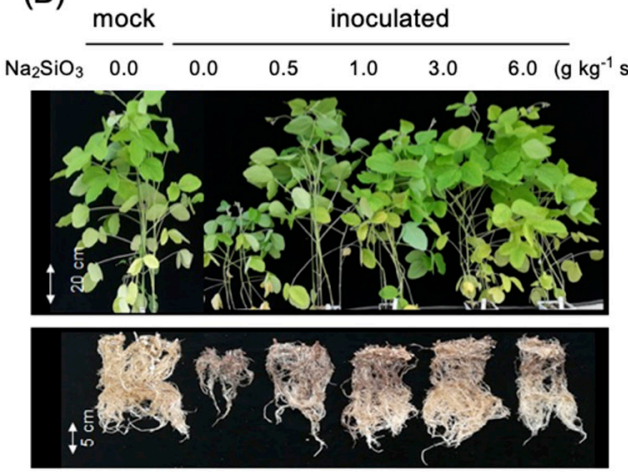

(C)

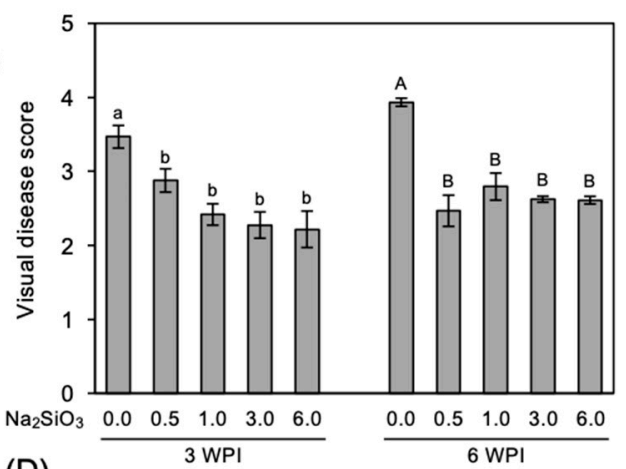

(D)

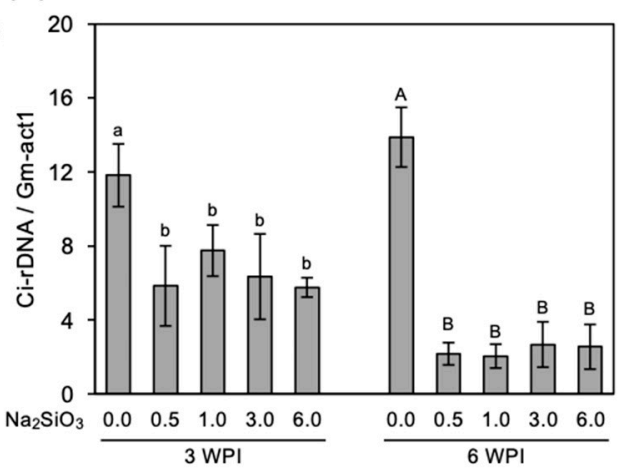

Figure 1. Plant growth parameters at 3 WPI (A) and 6 WPI (B), visual disease severity (C), and relative growth of Calonectria ilicicola in the roots of infected soybean seedlings at 3 and 6 WPI (D) $(n=12)$. Different letters (lowercase for 3 WPI, uppercase for 6 WPI) indicate significant differences among treatments at different sampling time points $(p<0.05)$, as per Tukey's HSD test.

Consistent with RCR severity, qPCR results showed a significant decrease in relative fungal growth in Si-treated plants by $50 \%, 34 \%, 46 \%$, and $51 \%$ at 3 WPI and by $84 \%$, $85 \%, 80 \%$, and $81 \%$ at $6 \mathrm{WPI}$, for $0.5,1.0,3.0$, and $6.0 \mathrm{~g} \mathrm{Na}_{2} \mathrm{SiO}_{3} \mathrm{~kg}^{-1}$ of soil, respectively (Figure 1D). The highest decrease in relative fungal growth was observed in plants treated with $0.5 \mathrm{~g} \mathrm{Na}_{2} \mathrm{SiO}_{3} \mathrm{~kg}^{-1}$ of soil. However, no significant difference in the extent of reduction of relative fungal growth was detected among Si-treated plants. 


\subsection{Correlation Analysis of Si Uptake and C. ilicicola Infection Parameters}

Compared to the un-inoculated control (mock), C. ilicicola infection significantly reduced Si uptake in the shoots of inoculated control plants $(0 \mathrm{Si})$ by $55 \%$ and $49 \%$ at 3 and 6 WPI, respectively (Figure 2A). The reduction in Si uptake was restored by Si application (Figure 2A). The highest Si content (an increase of 34\%) was detected in the un-inoculated control at a concentration of $3.0 \mathrm{~g} \mathrm{Na}_{2} \mathrm{SiO}_{3} \mathrm{~kg}^{-1}$ of soil at 6 WPI. There was no significant difference in Si uptake among the Si-treated plants at either sampling time point.

(A)

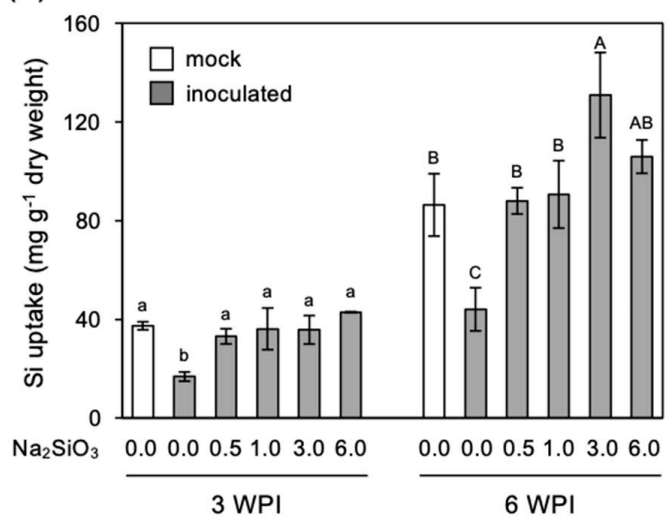

(B)

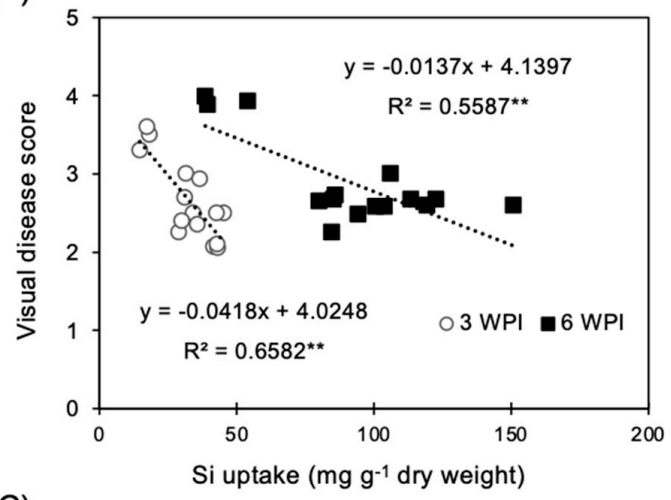

(C)

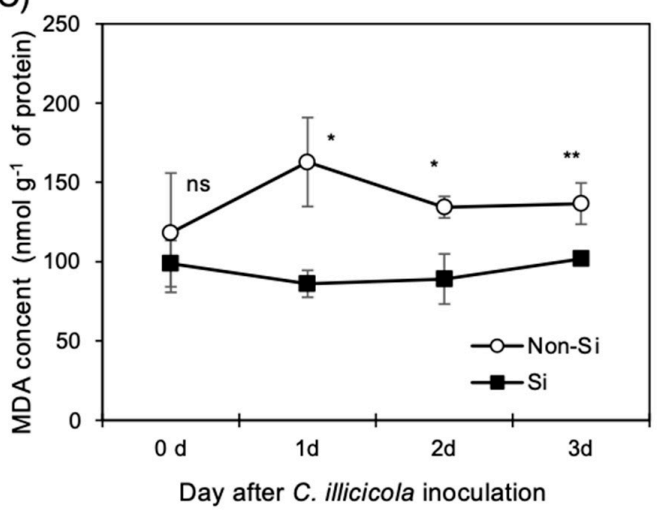

Figure 2. Correlation analysis of (A) shoot Si content and soil Si concentration, (B) disease severity at 3 and 6 WPI and Si uptake, and (C) MDA content in the roots and Si treatment $(n=12)$. Different letters (lowercase for 3 WPI, uppercase for 6 WPI) indicate significant differences among treatments $(p<0.05)$, as per Tukey's HSD test. Asterisks indicate significant difference between control (untreated) and Si-treated seedlings ( $t$ test, ${ }^{*}$ and ${ }^{* *}$ indicate $p<0.05$ and 0.01 , respectively).

Si uptake in the shoot was negatively correlated with RCR severity in the roots at both 3 WPI $\left(R^{2}=0.66, p<0.001\right)$ and 6 WPI $\left(R^{2}=0.56, p<0.001\right)$ (Figure $\left.2 B\right)$. 
MDA, the most abundant product of aldehydic lipid breakdown, indicates the level of stress and injury to cellular membranes. We found that C. ilicicola infection increased MDA accumulation at the early stages (1-3 DPI), which was significantly suppressed by $\mathrm{Si}$ treatment $\left(3.0 \mathrm{~g} \mathrm{~L}^{-1}\right)$.

\subsection{Effect of Si Application on Growth of Infected Plants}

As shown in Table 1, ANOVA of growth parameters revealed significant differences $(p<0.001)$ among Si concentrations, sampling time points, and their interaction. Plant growth parameters, including plant height, leaf area, shoot and root FW, and shoot DW, were significantly higher in Si-treated plants than those in the inoculated control plants (0 Si) at both sampling time points (Figure 3).

Table 1. ANOVA of the effects of Si concentration and sampling time point on plant growth and disease severity of infected plants.

\begin{tabular}{cccccccc}
\hline \multirow{2}{*}{ Source of Variation } & \multirow{2}{*}{$d f$} & \multicolumn{5}{c}{$p$-Values } \\
\cline { 3 - 7 } & & Plant Height & Leaf Area & Shoot FW & Root FW & Shoot DW & DS \\
\hline Silicon (Si) concentration & 4 & 0.0001 & 0.0002 & 0.0000 & 0.0000 & 0.0003 & 0.0000 \\
Sampling time point (T) & 1 & 0.0000 & 0.0000 & 0.0000 & 0.0000 & 0.0000 & 0.0024 \\
Si $\times$ T & 4 & 0.0250 & 0.0025 & 0.0016 & 0.0027 & 0.0034 & 0.0041 \\
\hline
\end{tabular}

(A)

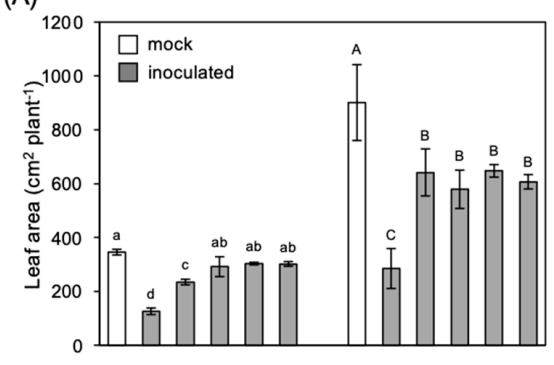

(C)

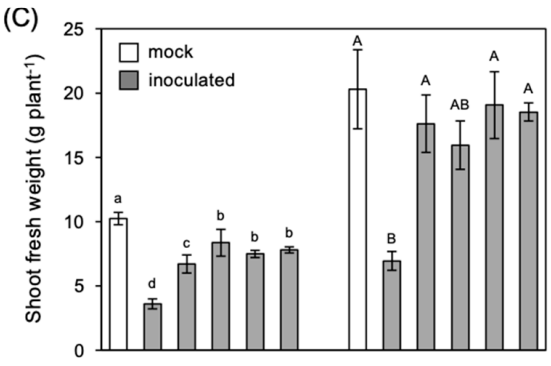

(E)

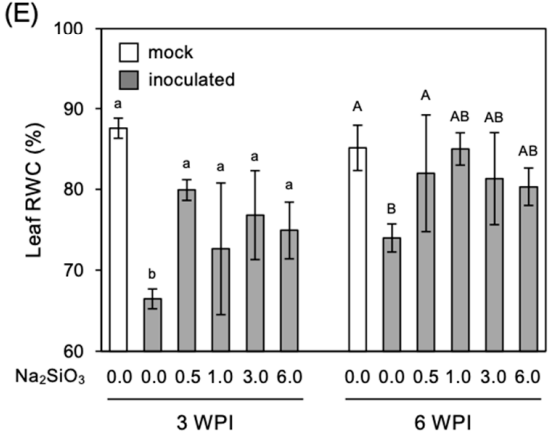

(B)

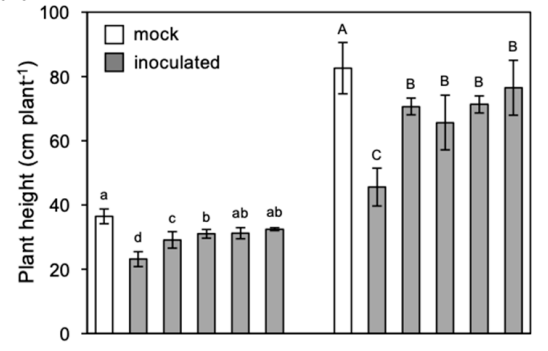

(D)
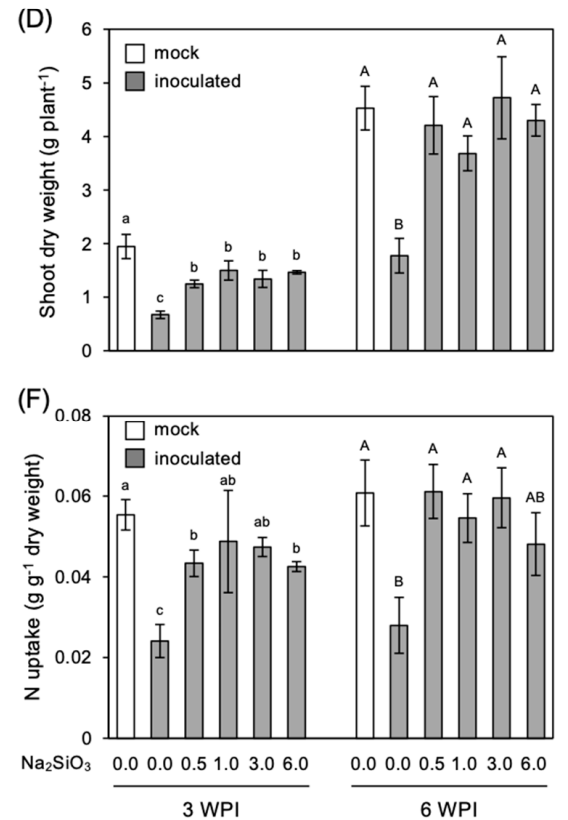

Figure 3. Leaf area (A), plant height (B), shoot FW (C), shoot DW (D), leaf RWC (E), and N uptake (F) of soybean plants at 3 and 6 WPI with Calonectria ilicicola $(n=12)$. Different letters (lowercase for 3 WPI, uppercase for 6 WPI) indicate significant differences among treatments $(p<0.05)$, as per Tukey's HSD test. 
Leaf growth was markedly reduced in inoculated control plants by $68 \%$ and $64 \%$ at 3 and $6 \mathrm{WPI}$, respectively, whereas $\mathrm{Si}$ application restored leaf growth to $12-32 \%$ at $3 \mathrm{WPI}$ and $29-36 \%$ at 6 WPI, when compared to un-inoculated controls (Figure 3A). Similarly, Si application restored the plant height of inoculated control plants from $37 \%$ and $45 \%$ to $11-20 \%$ and $7-20 \%$ (Figure $3 \mathrm{~B}$ ), shoot FW from $65 \%$ and $66 \%$ to $18-37 \%$ and $6-21 \%$ (Figure 3C), and shoot DW from $66 \%$ and $61 \%$ to $<5 \%$ and $23-36 \%$ (Figure 3D) at 3 and 6 WPI, respectively, when compared to the un-inoculated control plants.

Moreover, RCR notably reduced leaf RWC in inoculated control plants by $13 \%$ and $24 \%$ at 3 and 6 WPI, respectively (Figure 3E). In contrast, leaves of the Si-treated plants maintained a high RWC at both sampling time points, and no significant differences were observed among Si concentrations.

Similarly, RCR significantly $(p<0.05)$ reduced N uptake in the shoots of soybean plants by $56 \%$ and $54 \%$ at 3 and 6 WPI, respectively (Figure 3F); however, N uptake was greatly restored by most $\mathrm{Si}$ concentrations tested.

Root growth parameters were also significantly $(p<0.05)$ reduced in response to RCR; FWs decreased by $63 \%$ and $68 \%$, surface area decreased by $25 \%$ and $64 \%$, total length decreased by $43 \%$ and $64 \%$, and total tip number decreased by $31 \%$ and $71 \%$ at 3 and 6 WPI, respectively (Figure 4). However, again, root growth parameters, except for total tip number, were effectively restored by $\mathrm{Si}$ treatment (Figure 4).

(A)

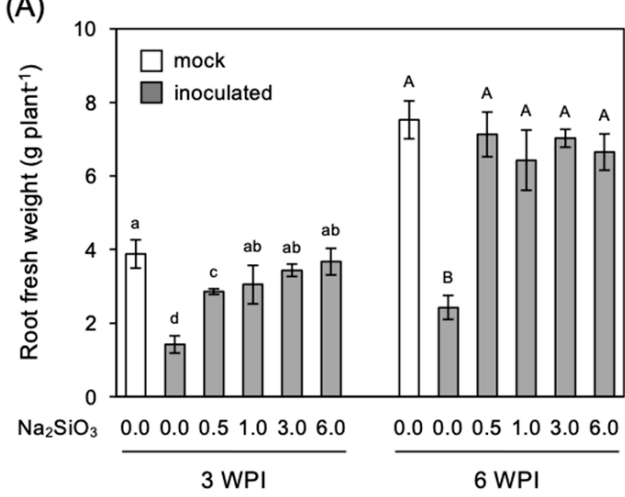

(C)

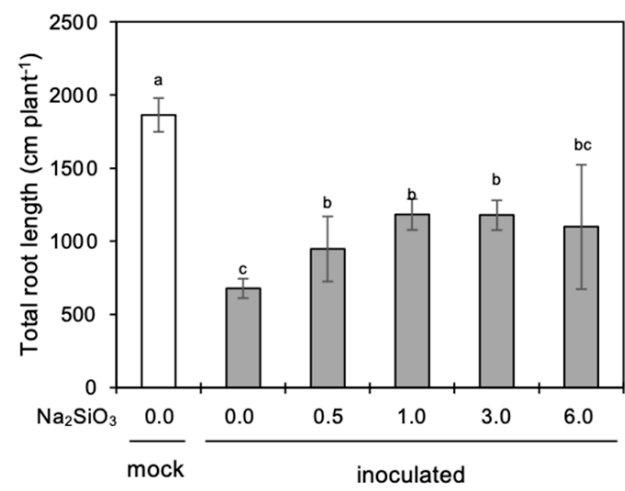

(B)

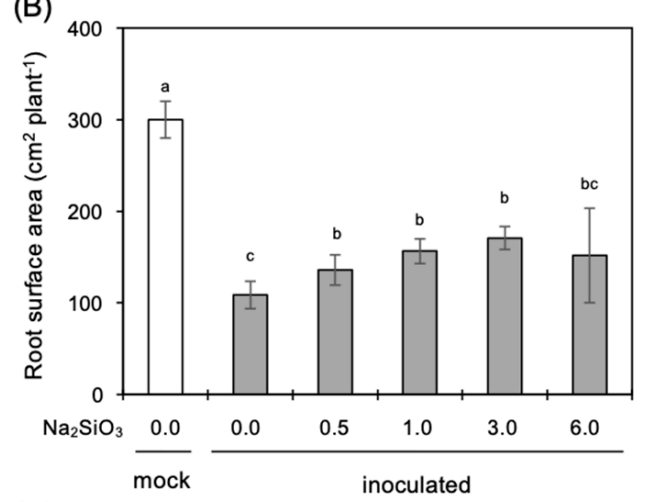

(D)

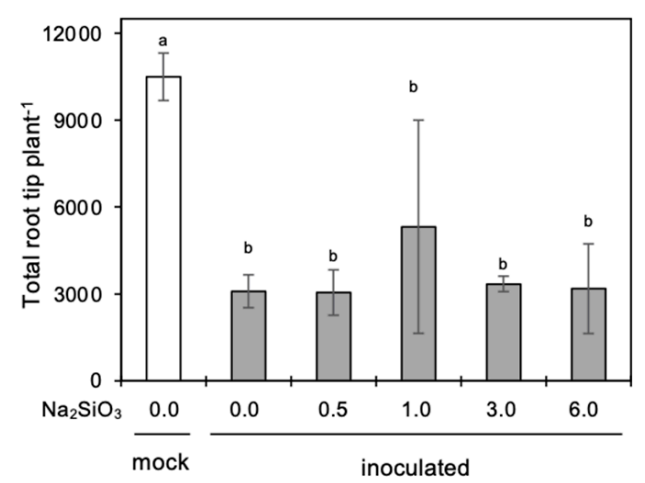

Figure 4. Root FW at 3 and 6 WPI (A), root surface area (B), total root length (C), and total number of root tips (D) of soybean plants at 3 WPI $(n=12)$. Different letters (lowercase for 3 WPI, uppercase for 6 WPI) at each sampling time point indicate significant difference $(p<0.05)$, as per Tukey's HSD test.

\subsection{Effect of Si Application on Seed Yield}

Infection with RCR significantly reduced the aboveground DW by $64 \%$ and seed yield by $79 \%$ in the inoculated control compared to the un-inoculated control (Figure 5). The reduction in aboveground DW and seed yield were markedly alleviated by Si application to $20-41 \%$ and $17-73 \%$, respectively. Moreover, both parameters increased with increasing 
Si concentration from 0.5 to $3.0 \mathrm{~g} \mathrm{Na}_{2} \mathrm{SiO}_{3} \mathrm{~kg}^{-1}$ soil; however, the corresponding values decreased with application of $6 \mathrm{~g} \mathrm{Na}_{2} \mathrm{SiO}_{3} \mathrm{~kg}^{-1}$ soil.

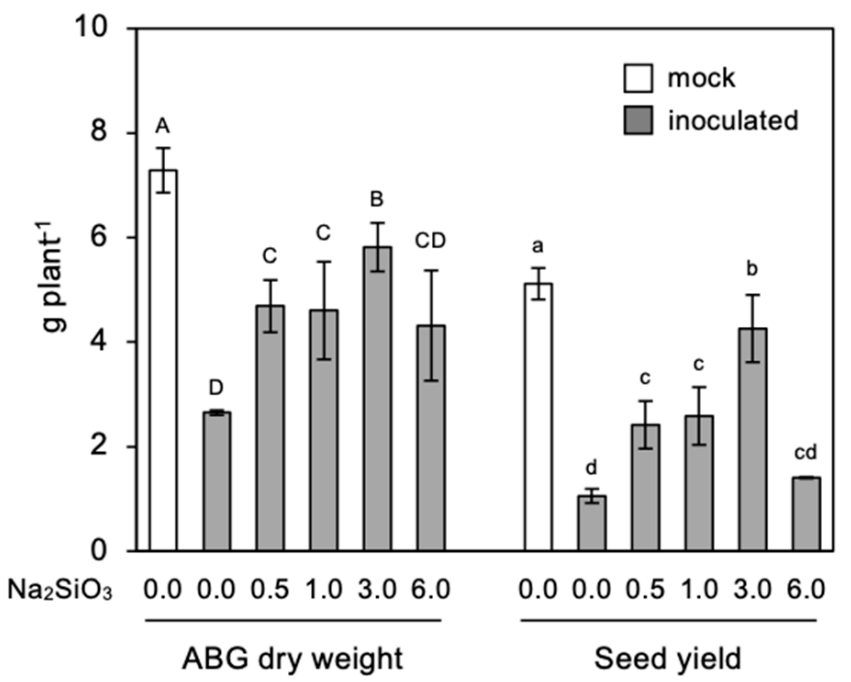

Figure 5. Aboveground DW (ABG dry weight) and seed yield of soybean plants $(n=12)$. Different letters (lowercase for $3 \mathrm{WPI}$, uppercase for $6 \mathrm{WPI}$ ) at each sampling time point indicate significant difference $(p<0.05)$, as per Tukey's HSD test.

\subsection{Effect of Si on the Growth of C. ilicicola}

The direct effect of different concentrations of $\mathrm{Si}$ on the growth of $C$. ilicicola are shown in Figure 6. As can be seen, $\mathrm{Si}$ concentrations up to $3 \mathrm{~g} \mathrm{~L}^{-1}$ did not show any inhibitory effect on the growth of C. ilicicola; indeed, a low concentration of $0.5 \mathrm{~g} \mathrm{~L}^{-1}$ actually increased fungal growth by $2.9 \%$ and $3.9 \%$ after 10 and $14 \mathrm{~d}$, respectively (Table 2). Thus, at subtoxic concentrations, Si seemingly acted as a nutrient supplement and promoted mycelial growth. However, a significant $(p<0.05)$ reduction in fungal growth was observed at $\mathrm{Si}$ concentrations from 6 to $10 \mathrm{~g} \mathrm{~L}^{-1}$; with a $>50 \%$ inhibition of linear growth being observed at $10 \mathrm{~g} \mathrm{~L}^{-1}$, whereas the $6 \mathrm{~g} \mathrm{~L}^{-1}$ treatment had a moderate effect. Furthermore, ANOVA results (Table 2$)$ showed a significant effect $(p<0.001)$ of $\mathrm{Si}$ concentration on the growth of C. ilicicola.

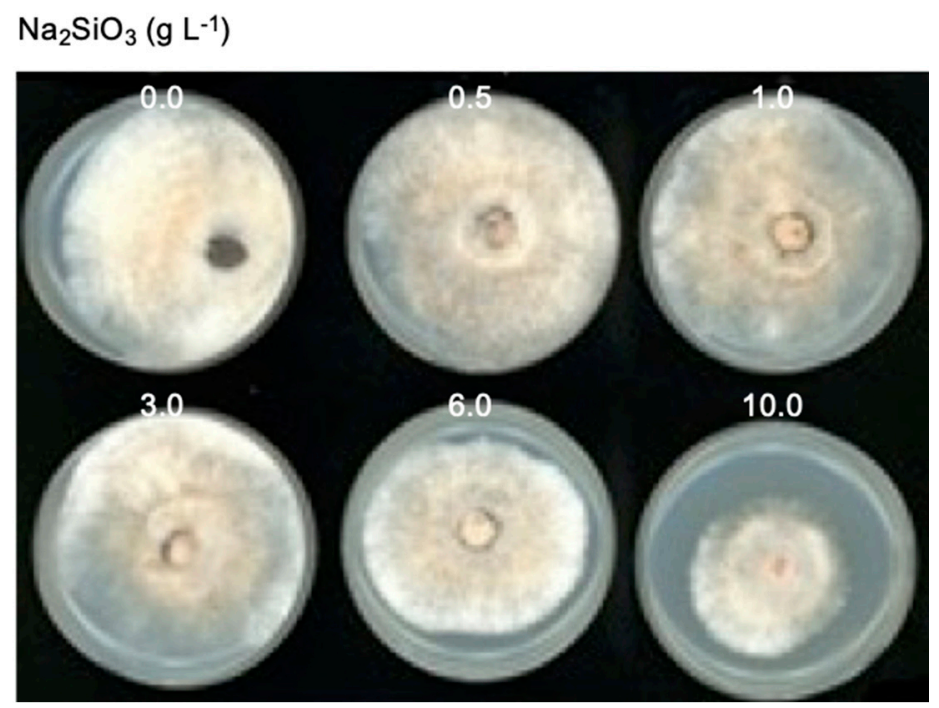

Figure 6. Antifungal effect of different concentrations of $\mathrm{Na}_{2} \mathrm{SiO}_{3}\left(\mathrm{~g} \mathrm{~L}^{-2}\right)$ on the growth of Calonectria ilicicola. 
Table 2. In vitro inhibition of the growth of Calonectria ilicicola at different concentrations of $\mathrm{Na}_{2} \mathrm{SiO}_{3}$.

\begin{tabular}{cccc}
\hline \multirow{2}{*}{ Treatments $\left(\mathbf{N a}_{\mathbf{2}} \mathbf{S i O}_{\mathbf{3}} \mathbf{~} \mathbf{~ L}^{-\mathbf{1}}\right)$} & \multicolumn{3}{c}{ Percent Inhibition } \\
\cline { 2 - 4 } & 4 Days & 10 Days & $\mathbf{1 4}$ Days \\
\hline 0.5 & -2.25 & -2.89 & -3.89 \\
1 & 2.01 & 7.27 & 0.00 \\
3 & 10.10 & 8.17 & 0.00 \\
6 & 32.22 & 18.19 & 12.45 \\
10 & 79.23 & 67.88 & 57.25 \\
\hline ANOVA & & $p$-value \\
\hline Source of variation & 4 days & 10 days & 14 days \\
\hline Si concentration & 0.0000 & 0.0001 & 0.00001 \\
\hline
\end{tabular}

\section{Discussion}

Despite the need for effective methods to control RCR in soybean, no resistant cultivars or effective fungicides have been developed to date. Previous studies have shown that Si application, as a prophylactic measure, effectively increases disease resistance in many plant species $[13,17]$. However, few studies have investigated whether Si can increase host resistance in legumes, such as soybean [20]. Therefore, in this study, we showed for the first time that the application of $\mathrm{Na}_{2} \mathrm{SiO}_{3}$ to the soil increased $\mathrm{Si}$ uptake in soybean plants, subsequently increasing resistance to RCR. These results highlight the effects of Si on RCR incidence, presenting a new, promising, and environmentally sustainable strategy for the control of soybean RCR.

We observed that $C$. ilicicola infection significantly reduced the uptake of $\mathrm{Si}$, which was restored by Si supplementation to the soil (Figure 2A). Moreover, Si content in the shoots was negatively correlated with RCR severity in the roots (Figure 2B). These results are consistent with the positive role of $\mathrm{Si}$ in disease resistance in a wide range of plant species [16,20]. We also found a significant accumulation of MDA upon C. ilicicola infection at the early stages of infection (1-3 DPI), which was suppressed by pretreatment with $\mathrm{Si}$ (Figure 2C). MDA is a well-known universal biomarker of lipid peroxidation of cellular membranes caused by reactive oxygen species (ROS) $[16,24,33]$. These results indicate that maintenance of ROS homeostasis and the integrity of cellular membranes are important underlying mechanisms of Si-mediated resistance in soybean plants against C. ilicicola. Furthermore, Si concentration $\leq 3 \mathrm{~g} \mathrm{~L}^{-1}$ had no direct inhibitory effect on $C$. ilicicola growth (Figure 6 and Table 2), whereas a low Si concentration $\left(0.5 \mathrm{~g} \mathrm{~L}^{-1}\right)$ in fact promoted the growth of $C$. ilicicola (Table 2). These observations suggest a priming effect of $\mathrm{Si}$ for enhanced resistance in soybean against RCR, unlike the direct inhibition of fungal growth in the soil.

A typical disease symptom of RCR is the loss of lateral roots [34], leading to a decrease in leaf RWC and plant wilting [35]. In this study, Si application significantly alleviated the root damage caused by C. ilicicola infection (Figure 1), as indicated by the significant restoration of root surface area, total root length, and root biomass, compared to the inoculated control plants (Figure 4). Leaf RWC and N uptake were also significantly restored upon Si application (Figure 3E). Overall, the protective effects of Si on the roots likely helped soybean plants to maintain, to a large extent, water (Figure 3E) and mineral nutrient uptake (Figure 3F), thereby maintaining plant growth and seed yield (Figures 3 and 4). Seed yield (Figure 5) increased with increasing $\mathrm{Si}$ concentration up to $3.0 \mathrm{~g} \mathrm{Na}_{2} \mathrm{SiO}_{3} \mathrm{~kg}^{-1}$, soil but it decreased at an $\mathrm{Si}$ concentration higher than $6 \mathrm{~g} \mathrm{Na}_{2} \mathrm{SiO}_{3} \mathrm{~kg}^{-1}$ soil, defining the range of $\mathrm{Si}$ concentration (0.5-3.0 $\mathrm{g} \mathrm{Na}_{2} \mathrm{SiO}_{3} \mathrm{~kg}^{-1}$ of soil) for the effective control of RCR in soybean.

\section{Conclusions}

Despite extensive efforts, to date, no effective agricultural practices have been established to control the soybean RCR. The results reported herein showed that $\mathrm{Si}$ application might provide an effective and sustainable solution to this problem. However, the best 
possible use of Si for soybean red crown rot control warrants further study to thoroughly elucidate the molecular mechanisms underlying Si-mediated crop protection against soybean RCR.

Author Contributions: C.-J.J. and K.T.W. conceived the research ideas, designed the experiments, and wrote the article; K.T.W., S.M., and M.K. performed the experiments and data analyses. All authors have read and agreed to the published version of the manuscript.

Funding: This study was supported by the research program on development of innovative technology grants from Project of the Bio-oriented Technology Research Advancement Institute (BRAIN; 01012B).

Institutional Review Board Statement: Not applicable.

Informed Consent Statement: Not applicable.

Data Availability Statement: Not applicable.

Acknowledgments: We would like to acknowledge the technical assistance of Mio Masuko and Miyuki Ishikawa.

Conflicts of Interest: The authors declare no conflict of interest.

\section{References}

1. Bel, D.; Sobers, E.K. A peg, pod, and root necrosis of peanuts caused by a species of Calonectria. Phytopathology 1966, 56, 1361-1364.

2. Crous, P.; Wingfield, M.; Alfenas, A. Cylindrocladium parasiticum sp. nov., a new name for C. crotalariae. Mycol. Res. 1993, 97, 889-896. [CrossRef]

3. Padgett, G.B.; Kuruppu, P.U.; Russin, J.S. Red crown rot. In Compendium of Soybean Diseases and Pest; Artman, G.L., Rupe, J.C., Sikora, E.J., Domier, L.L., Davis, J.A., Steffey, K.L., Eds.; The American Phytopathological Society Press: St. Paul, MN, USA, 2015; pp. $79-80$.

4. Guan, M.; Pan, R.; Gao, X.; Xu, D.; Deng, Q.; Deng, M. First report of red crown rot caused by Cylindrocladium parasiticum on soybean in Guangdong, Southern China. Plant Dis. 2010, 94, 485. [CrossRef]

5. Tazawa, J.; Takahashi, M.; Usuki, K.; Yamamoto, H. Nodulation during vegetative growth of soybean stage does not affect the susceptibility to red crown rot caused by Calonectria ilicicola. J. Gen. Plant Pathol. 2007, 73, 180-184. [CrossRef]

6. Nishi, K. Calonectria ilicicola, the causal pathogen of soybean red crown rot. MAFF Microorg. Genet. Resour. Man. No.21 Jpn. Engl. Summ. 2007, 1-13.

7. Ochi, S. Studies on the epidemiology and control of red crown rot of soybean. J. Gen. Plant Pathol. 2017, 83, 427-428. [CrossRef]

8. Sugimoto, T.; Kato, M.; Yoshida, S.; Matsumoto, I.; Kobayashi, T.; Kaga, A.; Hajika, M.; Yamamoto, R.; Watanabe, K.; Aino, M.; et al. Pathogenic diversity of Phytophthora sojae and breeding strategies to develop Phytophthora-resistant soybeans. Breed. Sci. 2012, 61, 511-522. [CrossRef] [PubMed]

9. Bajgain, R.; Kawasaki, Y.; Akamatsu, Y.; Tanaka, Y.; Kawamura, H.; Katsura, K.; Shiraiwa, T. Biomass production and yield of soybean grown under converted paddy fields with excess water during the early growth stage. Field Crop. Res. 2015, 180, 221-227. [CrossRef]

10. Kleczewski, N.; Plewa, D.; Kangas, C.; Phillippi, E.; Kleczewski, V. First report of red crown rot of Soybeans caused by Calonectria ilicicola (Anamorph: Cylindrocladium parasiticum) in Illinois. Plant Dis. 2019, 103, 1777. [CrossRef]

11. Roy, K.W.; McLean, K.S.; Lawrence, G.W.; Patel, M.V.; Moore, W.F. First Report of Red Crown Rot on Soybeans in Mississippi. Plant Dis. 1989, 73, 273. [CrossRef]

12. Jiang, C.J.; Sugano, S.; Ochi, S.; Kaga, A.; Ishimoto, M. Evaluation of Glycine max and Glycine soja for Resistance to Calonectria ilicicola. Agronomy 2020, 10, 887. [CrossRef]

13. Datnoff, L.E.; Deren, C.W.; Snyder, G.H. Silicon fertilization for disease management of rice in Florida. Crop Protect. 1997, 16, 525-531. [CrossRef]

14. Datnoff, L.E.; Rodrigues, F.A.; Seebold, K. Silicon and Plant Disease; APS Press: St. Paul, MN, USA, 2007; pp. $233-246$.

15. Cai, K.Z.; Gao, D.; Luo, S.M.; Zeng, R.S.; Yang, J.Y.; Zhu, X.Y. Physiological and cytological mechanisms of silicon-induced resistance in rice against blast disease. Physiol. Plant. 2008, 134, 324-333. [CrossRef] [PubMed]

16. Debona, D.; Rodrigues, F.A.; Datnoff, L.E. Silicon's role in abiotic and biotic plant stresses. Annu. Rev. Phytopathol. 2017, 55, 85-107. [CrossRef]

17. Fauteux, F.; Remus-Borel, W.; Menzies, J.G.; Belanger, R.R. Silicon and plant disease resistance against pathogenic fungi. FEMS Microbiol. Lett. 2005, 249, 1-6. [CrossRef] [PubMed]

18. Wang, M.; Gao, L.M.; Dong, S.Y.; Sun, Y.M.; Shen, Q.R.; Guo, S.W. Role of Silicon on Plant-Pathogen Interactions. Front. Plant Sci. 2017, 8, 701. [CrossRef] [PubMed]

19. Heine, G.; Tikum, G.; Horst, W.J. The effect of silicon on the infection by and spread of Pythium aphanidermatum in single roots of tomato and bitter gourd. J. Exp. Bot. 2007, 58, 569-577. [CrossRef] [PubMed] 
20. Putra, R.; Powell, J.R.; Hartley, S.E.; Johnson, S.N. Is it time to include legumes in plant silicon research? Funct. Ecol. 2020, 34, 1142-1157. [CrossRef]

21. Nolla, A.; Korndörfer, G.H.; Coelho, L. Efficiency of calcium silicate and carbonate in soybean disease control. J. Plant Nutr. 2006, 29, 2049-2061. [CrossRef]

22. Rasoolizadeh, A.; Labbe, C.; Sonah, H.; Deshmukh, R.K.; Belzile, F.; Menzies, J.G.; Belanger, R.R. Silicon protects soybean plants against Phytophthora sojae by interfering with effector-receptor expression. BMC Plant Biol. 2018, 18, 1-13. [CrossRef]

23. Guérin, V.; Lebreton, A.; Cogliati, E.E.; Hartley, S.E.; Belzile, F.; Menzies, J.G.; Bélanger, R.R. A zoospore inoculation method with Phytophthora sojae to assess the prophylactic role of silicon on soybean cultivars. Plant Dis. 2014, 98, 1632-1638. [CrossRef] [PubMed]

24. Telles Nascimento, K.J.; Debona, D.; Silveira, P.R.; Silva, L.C.; DaMatta, F.M.; Rodrigues, F.Á. Silicon-induced changes in the antioxidant system reduce soybean resistance to frogeye leaf spot. J. Phytopathol. 2016, 164, 768-778. [CrossRef]

25. Nascimento, K.J.T.; Debona, D.; França, S.K.S.; Gonçalves, M.G.M.; DaMatta, F.M.; Rodrigues, F.Á. Soybean resistance to Cercospora sojina infection is reduced by silicon. Phytopathology 2014, 104, 1183-1191. [CrossRef] [PubMed]

26. Arsenault-Labrecque, G.; Menzies, J.G.; Bélanger, R.R. Effect of silicon absorption on soybean resistance to Phakopsora pachyrhizi in different cultivars. Plant Dis. 2012, 96,37-42. [CrossRef]

27. Cruz, M.F.A.; Rodrigues, F.Á.; Diniz, A.P.C.; Alves Moreira, M.; Barros, E.G. Soybean resistance to Phakopsora pachyrhizi as affected by acibenzolar-S-methyl, jasmonic acid and silicon. J. Phytopathol. 2014, 162, 133-136. [CrossRef]

28. Nishi, K.; Sato, F.; Karasawa, T.; Sato, T.; Takahashi, H.; Nishi, K. (1999). Ecology and control of root necrosis of soybean caused by Calonectria crotalariae (Jpn. with English summary). Bull. Nat. Agric. Res. Cent. 1999, 30, 11-109.

29. Ochi, S.; Kuroda, T. Developing a qPCR assay for the quantification of Calonectria ilicicola in soil of soybean field. Trop. Plant Pathol. 2020, 46, 186-194. [CrossRef]

30. Sugano, S.; Sugimoto, T.; Takatsuji, H.; Jiang, C.J. Induction of resistance to Phytophthora sojae in soyabean (Glycine max) by salicylic acid and ethylene. Plant Pathol. 2013, 62, 1048-1056. [CrossRef]

31. Filella, I.; Llusia, J.; Pinol, J.; Penuelas, J. Leaf gas exchange and fluorescence of Phillyrea latifolia, Pistacia lentiscus and Quercus ilex saplings in severe drought and high temperature conditions. Environ. Exp. Bot. 1998, 39, 213-220. [CrossRef]

32. Elliott, C.L.; Snyder, G.H. Autoclave-Induced Digestion for the Colorimetric Determination of Silicon in Rice Straw. J. Agric. Food Chem. 1991, 39, 1118-1119. [CrossRef]

33. Corbineau, F.; Gay-Mathieu, C.; Vinel, D.; Come, D. Decrease in sunflower (Helianthus annuus) seed viability caused by high temperature as related to energy metabolism, membrane damage and lipid composition. Physiol. Plant. 2002, 116, 489-496. [CrossRef]

34. Akamatsu, H.; Fujii, N.; Saito, T.; Sayama, A.; Matsuda, H.; Kato, M.; Kowada, R.; Yasuta, Y.; Igarashi, Y.; Komori, H. Factors affecting red crown rot caused by Calonectria ilicicola in soybean cultivation. J. Gen. Plant Pathol. 2020, 86, 363-375. [CrossRef]

35. Yamamoto, R.; Nakagawa, A.; Shimada, S.; Komatsu, S.; Kanematsu, S. Histopathology of red crown rot of soybean. J. Gen. Plant Pathol. 2017, 83, 23-32. [CrossRef] 